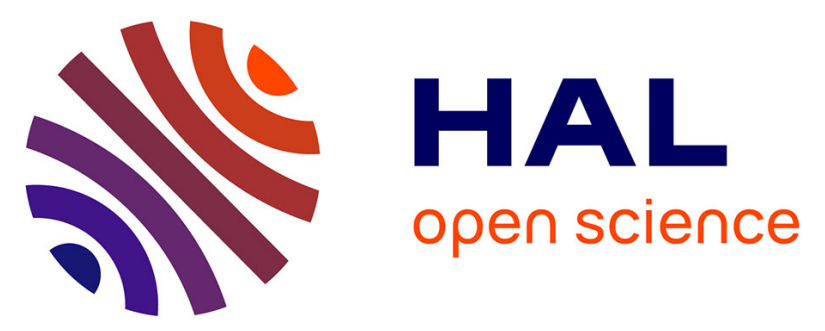

\title{
Fostering sustainable diets through a comprehensive approach of value-adding operations: What can vegetable box schemes contribute?
}

Caroline Huyard

\section{- To cite this version:}

Caroline Huyard. Fostering sustainable diets through a comprehensive approach of value-adding operations: What can vegetable box schemes contribute?. Journal of Cleaner Production, 2020, Journal of Cleaner Production, 256, pp.120615. 10.1016/j.jclepro.2020.120615 . hal-03256518

\section{HAL Id: hal-03256518 \\ https://hal.univ-lille.fr/hal-03256518}

Submitted on 10 Jun 2021

HAL is a multi-disciplinary open access archive for the deposit and dissemination of scientific research documents, whether they are published or not. The documents may come from teaching and research institutions in France or abroad, or from public or private research centers.
L'archive ouverte pluridisciplinaire HAL, est destinée au dépôt et à la diffusion de documents scientifiques de niveau recherche, publiés ou non, émanant des établissements d'enseignement et de recherche français ou étrangers, des laboratoires publics ou privés. 


\section{JOURNAL OF CLEANER PRODUCTION}

Fostering sustainable diets through a comprehensive approach of value-adding operations: what can vegetable box schemes contribute?

\section{Highlights}

- $\quad$ Vegetable box schemes link subscribers with producers on a long-term basis.

- $\quad$ Studies reported that they contribute to a healthier diet, but the effect is short-lived.

- We explored the effects of a box scheme combined with food preparation training.

- $\quad$ The participants’ eating patterns got more sustainable, except for animal proteins.

- $\quad$ These effects persisted as long as the box scheme was running.

\section{Abstract}

Food value chains have a major impact on the environment. Experimentation with what can be called "alternative production systems”, i.e. innovative production and consumption patterns,

15 involving actors within and outside supply chains, seems a potentially interesting way to reduce this impact. This study is based on the hypothesis that such systems may need to combine the provision of material goods with that of services, including skills, to end-users. In the specific case of a vegetable box scheme, promising effects were reported previously by a health study, but they were short-lived. We investigated the changes in a subscriber's diet when structured, time-limited food

20 preparation training was provided in addition to the boxes with the aim of finding out to what extent a vegetable box scheme could contribute to more sustainable eating patterns and what features it should have for these eating patterns to be lasting. We interviewed 11 participants in such an experimental box scheme twice, while the box scheme was running and several months after its end. The participants reported changes that suggest their diet got more sustainable, and these effects

25 persisted as long as the box scheme was running. A theoretical framework is proposed, and pathways for generalisation are suggested. 


\section{Keywords}

Food supply; eating; dietary change; box scheme; food sustainability; sustainable diet

\section{1. Introduction}

Food value chains have a major impact on the environment, be it in terms of greenhouse gas emissions, soil acidification, or eutrophication (Poore and Nemecek, 2018). This is a wellknown and extensively researched production challenge. Scholars now suggest that a more holistic and multi-perspective approach has to be developed to better identify means to reduce the

35 environmental impact of food value chains (Schanes et al., 2016). Two additional perspectives have emerged, highlighting the need to address a "consumption challenge" and a "socio-economic challenge” (Garnett, 2013). They relate respectively to the need for changes in people’s diet, and to the need for changes in the governance of food systems. The design and implementation of alternative diets that are healthy while reducing agricultural greenhouse gas emissions and land

40 clearing is instrumental in this respect (Tilman and Clark, 2014).

Scholars who have researched the environmental performance of food production have pointed to the need to consider all stakeholders. Environmental performance in general depends indeed on improving standards and cooperation between food manufacturers, retailers, NGOs, and governmental and farmers' organisations (Smith, 2008). The performance of food supply chains in

45 particular depends on eight key characteristics: devices/software, eco-innovation, organisational culture, warehousing, transportation, food loss/waste, equipment, and regulation, the two most important being eco-innovation and loss reduction (Wu and Huang, 2018). Those also are the factors whose connection to the consumers is the strongest. Recent research take stock of these results and indicates that a production-only approach underestimates the efficiency losses associated

50 with consumption, and that consumption should be better integrated (Schanes et al., 2016). 
On the consumption side, scholars pointed to the need for consumers to change their habits in a number of ways, including taking into account the environmental consequences of food choices (Shi et al. 2018), accepting to pay a higher price for more environmentally efficient products (Tait et al. 2016), and choosing local products (Granvik et al., 2017). They identified a range of ways to 55 encourage consumers to make more sustainable choices, such as incentivising or disincentivising choices through fiscal measures, modifying the governance of consumption through regulation, and changing the architecture of choice through consumers' education based on community projects and campaigns (Garnett et al., 2015). A major finding, and a challenge for this strand of research, is that, although a profound change in the contemporary diet of high-income countries is increasingly

60 identified as an instrumental approach for reducing the environmental impact of food (Tilman and Clark, 2014), environmental impact is not a major concern in purchasing decisions. Health is more important (Hoek et al., 2017), even among consumers whose choices are more environmentally friendly (Baudry et al., 2017). This points to the need for approaches that would better connect consumption and production with the aim to deeply influence consumers’ diets.

The three perspectives that currently shape the challenge of reducing the environmental impact of food value chains appear to have opposite strengths and weaknesses. Actions on the sustainability of production processes tend to be effective but are limited by uncertainties related to consumer behaviour (Schanes et al., 2016) whereas actions on consumer behaviour and food system governance have the potential to lead to a significant reduction in the environmental impact of food

70 but are considered more difficult to devise and to implement (Garnett et al., 2015). To overcome this dilemma, it seems fruitful to address the environmental impact of food value chains with research strategies that take consumption and production into account simultaneously and address the whole supply chain. This is in line with the need for structural change that scholars have evidenced regarding sustainable consumption and production in general (Tukker et al., 2008). As 75 scholars increasingly highlight the importance of considering the environmental impact of diets 
(Tilman and Clark, 2014), it seems worth asking: Could changes at some key stages of the supply chain have an impact on consumer behaviour and more specifically on consumers’ diet?

Experimentation with what will be referred to here as “alternative production systems”, i.e. innovative production and consumption patterns, involving actors within and outside supply chains,

80 seems a potentially interesting way to fill this gap and reduce the environmental impact of food value chains. These alternative production systems can be expected to act by reducing the environmental impact of value-adding operations (e.g. by reducing losses or distances travelled) and by changing consumers' eating habits (e.g. by diversifying their diets or reducing the share of highly processed foods). Among these alternative production systems, the subscription to a weekly

85 basket of vegetables (a vegetable box scheme), which links customers to a local producer or group of local producers on a long-term basis, seems to have the potential to transform diets. It is local and tends to foster coordination between the participating producers and the subscribers through the planning of the boxes' content. A health study by AbuSabha (2016) reported an increase in vegetable and fruit consumption, an increase in the diversity of vegetables and fruit, and a reduction

90 in food spending among new subscribers to a vegetable and fruit box scheme at the end of the first three months (but not any longer 12 months after the start of the subscription). These effects are promising, as they support the improvement of the sustainability of food, but they only partially overlap with them and they were short-lived.

To our knowledge, no similar study has been conducted from an environmental 95 perspective. To date, existing studies on vegetable box schemes have investigated the production and the consumption sides separately. On the production side, scholars have looked at the environmental performance (Markussen et al., 2014), scalability (Milestad et al., 2017), or economic viability (Thom and Conradie, 2013) of this type of production. On the consumption side, scholars have focused on the ethical values of the subscribers. These values may refer to buying 100 what they perceive as "local” or “quality” products (Brown et al., 2009) and do not necessarily 
relate to environmental concern but rather to a social norm (Unčovská and Ulčák, 2015). These studies are based on the usual subscribers of vegetable box schemes, who tend on average to be better off than the general population, and although their eating habits, their concerns, and their attitude seem to evolve under the influence of the subscription, the concrete mechanisms eliciting 105 this evolution have not been described so far. The conditions for vegetable box schemes to transform consumers' diets beyond the first months of subscription still have to be explored, specifically in the case of mainstream consumers, whose values do not place environmental sustainability as a priority. This was the purpose of our study, whose objective was to determine what features a vegetable box scheme should have to support a long-lasting change of ordinary 110 consumers' food habits towards more environmentally sustainable diets.

The study is based on the general hypothesis that production systems that promote more sustainable lifestyles are ones that combine the provision of material goods with that of services, including skills, to end-users. In the specific case of a vegetable box scheme, we hypothesised (1) that the reported effects of a vegetable box scheme on the diet of subscribers were short-lived

115 because these subscribers did not have the relevant cooking skills to deal with it in an efficient way and were discouraged after a few weeks and (2) that a structured, time-limited training course should be able to provide subscribers with the food preparation skills necessary to process the weekly supply of vegetables in the box in a satisfactory way, so that the capacity to cook vegetables - and the ensuing healthier and more environmentally sustainable diet - should last long after the 120 end of the training course.

The research questions addressed by the study were: To what extent can a vegetable box scheme contribute to more sustainable eating patterns? What features should it have for these more sustainable eating patterns to be long-lasting? The research strategy to answer these questions is built on the work of Boltanski and Thévenot (2006) and their concepts of "test" and "justification".

125 A test is a a disruption of the ordinary course of action that makes visible functions or ways of 
thinking that were not visible when everything was going as usual. Justification refers to the way people account for how they reacted to the test, and the reasons that led them to react this way. These concepts are particularly useful to investigate everyday practices anchored in infrastructures or processes. The general idea is to create a new situation for participants to experience, and to

130 collect in-depth qualitative data on how the practices evolved and how the participants account for these changes. For the purpose of this study, a box scheme combined with a cooking training was specifically designed and offered to the participants, in order to investigate the impact of this type of food supply on their diet and segregate the role of the individual components.

\section{2. Methods}

The research design combined a longitudinal experiment and a qualitative approach. The longitudinal experiment involved setting up and monitoring an experimental vegetable box scheme consisting of a subscription to a basket of organic and local vegetables combined with a timelimited, eight-month-long training course in food preparation. This experimental box scheme lasted

140 for eight months. The participants were asked to describe what changes they had noticed in their food habits and their diet five to seven months after the beginning of the experimental box scheme (short term), and eight to ten months after the end of this box scheme, i.e. 16 to 18 months after its start (long term). The qualitative approach referred to the type of data collected. The research collected a very large amount of data on each case, in order to identify the actions performed by the

145 respondents, and the reasons why these actions had been taken, following the test-justification pattern of Boltanski and Thévenot (2006) described above. As in any qualitative research opening a new field, the questions asked were based on hypotheses, were structured and followed a rigorous and logical sequence, but open room was left for respondents to provide their answers, so as to collect unexpected information. 
To collect data on a population that is not particularly sensitive to environmental issues, and avoid repeating the results of previous studies on box schemes, the recruitment of the participants targeted people who consumed few fruits and vegetables, who did not have a subscription to a vegetable box scheme upon enrolment in the study and who had a low probability of having already had one, and who were more interested in gaining cooking skills than in getting a

155 low-priced subscription. This strategy was also intended to avoid a ceiling effect: for effects to be observed, the participants had to start from a low enough level of sustainable food consumption. An easily identifiable population that met these criteria was a population of students and young workers. In general, such people live alone and have had to cook on their own for a relatively short time, so their exposure to a vegetable box scheme and their cooking skills tend to be low, and it is

160 well established that their fruit and vegetable consumption is generally low as well (Larson et al., 2012).

The experimental vegetable box scheme was presented and offered as cooking training to students and recent university graduates from the Lille region and the Calais region in the north of France. The provision of food preparation skills was the key differentiating characteristic with 165 respect to the existing box schemes in the area. The training was designed to provide the participants with the means to improve the sustainability of their diet in a number of ways that they could prioritise according to their own needs (more fruit and vegetables, more variety, more homecooked meals, a more balanced diet, less meat and more legumes, etc.). Food preparation skills were provided to the participants in two ways: a collective, time-limited training course consisting 170 of a structured series of monthly four-hour food preparation workshops over eight months, each aimed at the acquisition of a specific set of skills of growing difficulty, which brought together the same group of participants under the guidance of a dietician-trainer, and an individual transmission of information, through information leaflets and e-mails that the participants received on a weekly or monthly basis. The training course provided (1) food preparation techniques and skills, and 
175 (2) organisational skills including the means to organise one’s food supply and to plan one’s food preparation work.

Upon enrolment, the participants were informed about the research project and the data that would be collected, they were given the opportunity to ask questions, and then they signed a consent form. By signing this form, they committed themselves to participating in the training course and to receiving a basket each week for eight months, as well as to contributing to the cost of the training course and baskets (in the latter case, their contribution gradually increased from 20\% of the price usually charged for such baskets to $80 \%$ in the last two months of training). The participants were recruited through various channels, including posters on campuses, information booths during university welcome days, newsletters in the universities of the region, and

185 announcements in other newsletters. The experimental box scheme was offered to two successive classes of participants. For the first class, the participants were recruited mainly through an online questionnaire, the main purpose of which was to better understand students' eating habits and needs. This questionnaire allowed respondents interested in the training to contact the trainer. For the second class, the participants were recruited mainly through an announcement on a mailing list for

190 students and young professionals interested in the social economy and environmental issues. The first class brought together groups of six participants in Lille and four participants in Calais. The second class brought together a group of six participants in Lille. Importantly, the majority of these participants (with only two exceptions) were attracted by the cooking workshops rather than by the box scheme. Their goals were to have a healthier diet (eating more vegetables), to have a more 195 pleasant diet (with more variety and more fresh produce), and simply to learn how to cook (learning to cook vegetables and learning to prepare more complex dishes than they usually did). The majority of the participants (11 out of 16) were not attracted by the fact that the vegetables met organic certification standards. Several of the participants expressed the view that consuming 
organic products as such is elitist and supports a two-tier society (which they opposed) and others

200 believed the organic certification is not trustworthy.

Data on changes in food consumption and food preparation habits were collected by indepth telephone interviews with the participants twice: firstly after five to seven months of using the experimental box scheme, and secondly eight to ten months after the end of the scheme. These indepth qualitative interviews focused on (1) how participants fed themselves and prepared food

205 (including purchasing and organisation-related topics) before, during and after the training; (2) the resources they used for this purpose (kitchen utensils and appliances, cookbooks, internet sites, etc.); and (3) the specific changes they might have noticed during the training and the months that followed regarding the way they fed themselves and prepared food. Seven participants (out of ten) from the first class and four participants (out of six) from the second class took part in both rounds 210 of interviews.

Data analysis used two techniques. The interviews contained data on four transitions with respect to the participants' food acquisition: (1a) from a conventional food supply system to the experimental box scheme; (1b) from a classical box scheme to the experimental box scheme (this transition was not investigated, as it was experienced by only one participant); (2a) from this

215 experimental box scheme to a mainly conventional food supply system (without a box scheme or training); and (2b) from this experimental box scheme to a classical box scheme only (without training). These transitions were used as “tests” (Boltanski \& Thévenot, 2006), which evidence the concrete changes that the participants experienced and how these changes influenced the sustainability of their diet. The move from one food supply system to another involved a 220 reorganisation of the participants' food habits, whereby the nature of these food habits, what they involved on a material plane and their reasons became visible.

\section{Figure 1. Food supply system transitions of the participants}




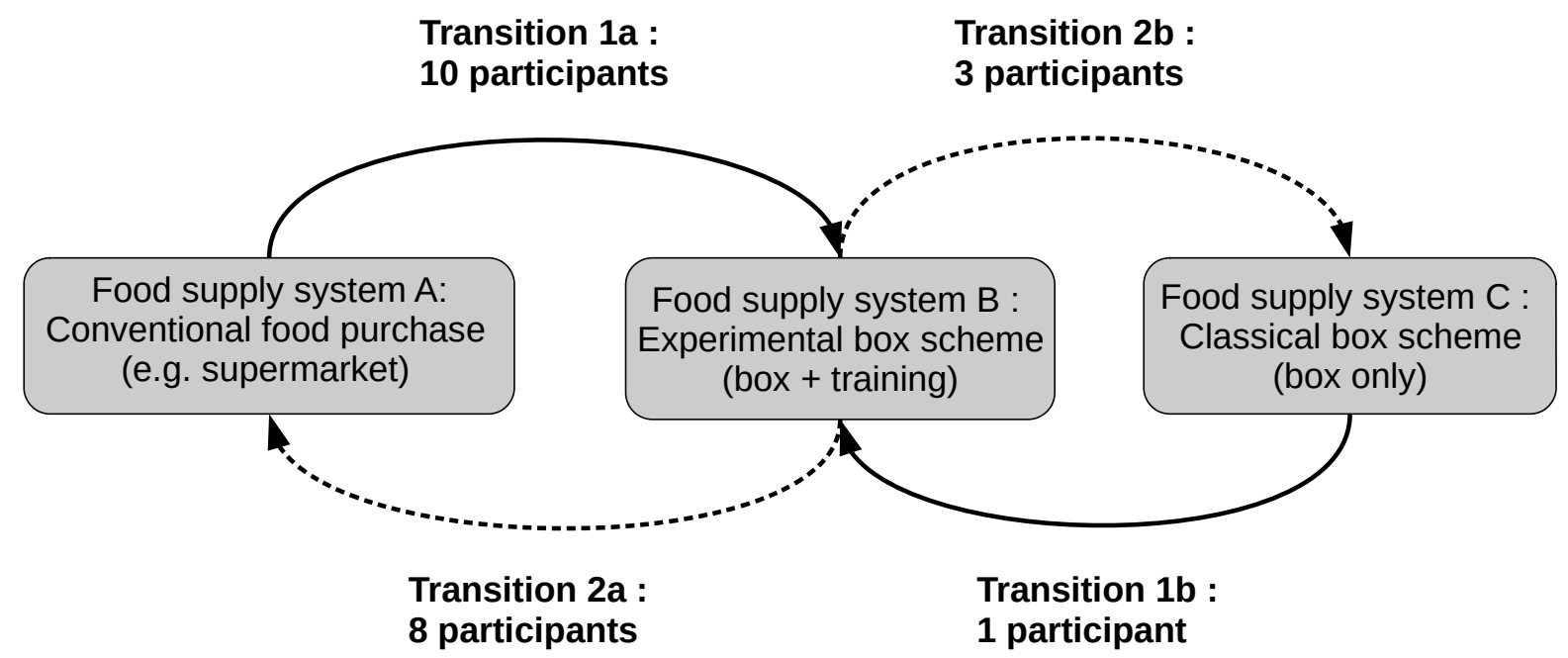

The coding process focused on these transitions and on the identification of all the concrete changes that the participants reported and that were relevant to food sustainability. The analysis followed the principles of Grounded Theory (Corbin \& Strauss, 2008). The data were coded line by line with a focus on the changes reported by the participants. The codes were then compared and

230 grouped into categories. These categories were compared to build a conceptual framework providing an understanding of the participants' concerns and actions.

\section{Results}

Of the 16 young adults who participated in the project, 11 could be interviewed twice. The 235 participants' socio-demographic characteristics are presented in Table 1. Eight to ten months after 
the end of the training, three participants reported a high consumption of vegetables, four reported an intermediate consumption and four reported a low consumption. In each of these three categories, there were participants living in a poorly equipped room and participants living alone. These characteristics can thus not be considered as hidden variables to explain the participants' competences and consumption of vegetables.

Table 1. Participants' socio-demographic characteristics

\begin{tabular}{|lll|}
\hline Variable & Value & $\begin{array}{l}\text { Number of } \\
\text { participants }\end{array}$ \\
\hline Gender & Female & 4 \\
\hline Activity at the time of the training & Male & 7 \\
\hline & Undergraduate & 3 \\
\hline Social context of housing at the time of the training & Plone & 2 \\
\hline & Lostgraduate & 5 \\
\hline Material context of housing at the time of the training & Students' room & 6 \\
\hline & Apartment & 5 \\
\hline
\end{tabular}

The transition from a conventional food purchase to the experimental box scheme

245 (Transition 1a) could be fully observed for 10 out of 11 participants, as one student already had a subscription to a vegetable box scheme (transition 1b). A return to a conventional food supply system was observed for eight participants (transition 2a), as three participants retained a box scheme after the end of the experimental one (transition 2b). Since the number of participants is relatively small and participants were going through a period of their lives during which many 250 personal changes occur (e.g. entry into working life or couple life), the analysis focuses on the most 
widely observed changes (i.e. changes reported by at least three participants), which are indeed most likely to be related to the transitions from one food system to another, and not to personal changes that are happened independently.

\section{1. Changes induced by the transition from a conventional food supply system to the experimental box scheme (Transition 1a)}

This transition involved 10 participants. These participants mentioned five changes in their eating habits, two of which related to their consumption habits and three to their organisational habits. They (1) observed an increase in their consumption of fresh vegetables, (2) observed an increase in the diversity of these vegetables, (3) started making shopping lists and planning meals,

260 (4) started scheduling a specific time for meal preparation and (5) noticed a reduction in the cognitive burden related to buying food.

The most frequently mentioned change related to the quantity of fresh vegetables eaten by the participants. For nine out of ten, this quantity increased significantly with the box scheme. As one participant (participant 5) put it:

265 Question: Have you noticed any changes in your habits and diet? Answer: Well, yes (laughs)! Because I eat vegetables much more often, and much more easily. Because having them at hand directly changes a lot of things.

It is difficult to measure the increase precisely, and this is not an objective of this study as such. However, five out of the nine participants stated that their consumption of fresh vegetables increased from a very low level of a few hundred grams (eating fresh vegetables less than once a week) to an average of one to three kilograms per week (depending on the season and on whether the content of the box was shared with a roommate or consumed entirely by the participant). The other participants also described an increase, but it is not possible to quantify it from the available data. 
The second most frequently mentioned change related to the diversity of the vegetables eaten by the participants. For eight out of ten, this diversity increased significantly with the box scheme. The participants believed much of this increase was due to the box scheme, as this participant (participant 8) explained:

And not choosing is like ... It is a constraint that ... I mean, it forced me to diversify, I would say (laughs)! Because I didn’t necessarily want to eat those things.

In light of the contextualising elements provided by the interviews, it seems that this diversification may be attributed to three mechanisms, two of which are related to the box scheme and one to an improvement in cooking skills resulting from the workshops. (1) The weekly boxes contained vegetables that the participants believed to be less frequently present in the distribution channels they were used to (e.g. squash, Jerusalem artichokes, kohlrabi, swede, parsnips). (2) The weekly boxes contained vegetables that the participants would not have bought spontaneously, either because they do not know how to prepare them (participant 1, for example, said: “When you see them at the market, you don't think, I'll buy that. You say to yourself, 'Is it edible?'”), or because they do not like them. As the box scheme forced them to buy these vegetables, they often tried to push themselves to eat them, and frequently discovered they actually enjoyed them. (3) This effort was indeed supported by the workshops, which enabled many participants to find ways to prepare and enjoy vegetables that they thought they did not like (participant 1 said: "I try to find recipes to somehow make some vegetables more acceptable, give them a different taste"), that they did not know how to prepare in large quantities (e.g. cabbage or squash) or that they did not know how to fit into the structure of their meal (e.g. salad or radish eaten as a starter).

A third change related to shopping practices. Seven out of ten participants said they got into the habit of making a shopping list and planning their meals each week. These participants all reported that making the shopping list consisted of defining how they would supplement the 
vegetables from the box in order to make complete meals, and what ingredients they would need to prepare these meals. One participant (participant 4) described this process as follows:

And what [the training] has changed in my habits is my shopping list. Because, as a result of the box scheme, I would make a shopping list. And it started from the vegetable basket. So, on Monday evening, I would go to the [vegetable basket supplier's] site to see what the content of the basket would be, and from there, I would structure, decide what kind of meat I was going to buy ...

The participants also stated that they felt this new shopping organisation had helped them reduce waste, because they bought food products based on decisions they had made about how and when they would prepare and eat them.

A fourth change related to the preparation of meals. Four out of ten participants said they got into the habit of planning cooking time and therefore frequently had home-cooked meals prepared with raw produce. As one participant (participant 11) described:

Question: Is the box scheme something you would like to carry on with?

Answer: Yeah, yeah, yeah. I used to make fun of a lot of my friends who used to do it (he laughs), but it really gives you a rhythm. It forces, well ... No, it doesn't force you, it's an opportunity to cook. You know that on a given day, something will unlock in your head. On Thursday evenings, I know there are vegetables, I always think about setting a time over the weekend when I can cook these vegetables while they are fresh, or at least prepare them so that they keep a little longer.

It can be assumed that more participants experienced this change, as those who described it explained that they planned this cooking time along with the week's meals and food purchases. 
Lastly, a fifth change related to the cognitive burden of the purchase decision. Three

330 they put it. As one participant (participant 4) stated:

Question: Could you tell me what the box scheme has changed in your habits?

Answer: Well, it didn't bring me too many constraints. I think it's of a supermarket was "complicated" for them: (1) they did not know what to buy; (2) in order to avoid overspending, they made trade-offs that they considered unsatisfactory (by taking first-price products when they had bought products that they considered expensive or by giving up on certain purchases, often vegetables); (3) it was difficult for them to buy new products out of fear of the unknown, ignorance of the preparation process or fear of exceeding their budget; and (4) they perceived all these questions as highly energy-consuming.

The experimental box scheme thus induced several changes. The significant increase in the quantity and diversity of fresh vegetables in the participants' diets as a result of the box scheme was anticipated. The changes induced in the daily organisation of the participants (planning the content of meals, making a shopping list, planning cooking time and a reduced cognitive burden) were anticipated as well. They initially were among the learning objectives assigned to the workshops but the box scheme seems to have played a major role. 


\section{food supply system (transition 2a)}

This transition involved eight participants. These participants mentioned three changes that corresponded to and reverted the changes described for the first transition (transition 1a). Two changes related to their food consumption habits, and one related to their organisation. They noticed (1) a decrease in the quantity of fresh vegetables they ate, (2) a reduction in the diversity of these vegetables and (3) a decrease in the time they spent cooking, which implied a decrease in the proportion of home-cooked meals in their diet.

The most frequently mentioned change related to the quantity of fresh vegetables in the participants' diets. Seven out of eight participants said that this quantity decreased after the end of the box scheme (and for two of these participants, it went down to almost zero). This applies both to participants who ate very few vegetables at the beginning of the study and to participants who used to eat vegetables frequently, as illustrated by these two participants:

Participant 1 (used to eat very few vegetables before the training): "I would say we cook fewer vegetables now. Fewer vegetables than before. I still buy some from time to time and cook vegetables. But much less often than when we had the vegetable baskets.”

Participant 4 (used to eat vegetables frequently before the training): “I clearly couldn't keep up with the rhythm of the imposed vegetable baskets. Because having a basket with a fair amount of vegetables every week forces you to eat a lot of vegetables.”

Two participants described the reasons for the decrease in their vegetable consumption. For one participant (participant 2), the cognitive burden of choice seems to have been a significant barrier:

Question: Can you say what made it difficult for you to carry on buying vegetables on a regular basis?

Answer: Well, in fact, in the baskets, we already had preselected vegetables, it was easier. And so, in the store, the vegetable 
department is so big that ... In the end, you don't necessarily know what to buy. It's mostly that, actually. I didn’t necessarily know what vegetables to buy.

Question: Okay, so the box scheme didn't teach you to make your own choice when in the store?

Answer: Yes, that's it. We knew what vegetables we were going to have for the next week, so we could already plan, we already knew what we were going to do, we didn't need to choose [original emphasis], in fact.

For two other participants, the difficulty rested in their perception of the price of vegetables. When purchasing decisions are frequent, typically once a week or more, attention to vegetable prices seems to be higher and to lead to the temptation to save money by cutting down on vegetables. The decision to purchase fresh vegetables is then potentially called into question each time the participants go shopping, as illustrated by this participant:

Participant 4: “And then there is also the fact that ... committing like last year to have a basket that we pay for every month, we give the cheque and then we get our basket ... Financially I felt better about investing in vegetables because it was the programme, because there was a special price for the box scheme and because we were committed from the beginning and the basket arrived every week. Whereas now, when I shop, I tend to want to save a little money here and there. For example, I'm not going to buy lettuce and endives, as I had in the basket, I’ll just have endives.”

Only one participant who no longer had a box scheme believed that he had maintained a level of vegetable consumption similar to the one he had with the box scheme, and it is worth mentioning that this participant bought the vegetables he needed at the weekly market.

The second most frequently mentioned change related to the diversity of the vegetables in 410 the participants' diets. The six participants who had continued to eat vegetables frequently but who no longer subscribed to a box scheme said that this diversity had decreased after the end of the 
improved box scheme implemented for the purpose of the study. This is illustrated well by one participant (participant 4):

There was diversity in the basket. When I shop now, I don't have the same diversity. Vegetables like parsnips, all that, it's all gone. Those vegetables, I would say, if I'm not pushed to eat them, I won't decide to eat them by myself. So here [...], yes, I would say that there is a change. I would say that there is especially a ... Ah, that's not the word, but ... Yes, there is an impoverishment. But ... The good thing is that I notice it.

Participants seemed to have stopped buying vegetables they were not used to or did not really appreciate, whereas they would used them when they received them with the box scheme.

A third change related to home cooking. Seven out of eight participants reported eating home-cooked meals less frequently than during the experimental box scheme period. Six of them believed this was because they were, in their own words, "less organised" or "took less time to cook". By contrast, the box scheme helped them maintain a kind of self-discipline, through a mechanism that one of the participants (participant 4) described as follows:

When we had the basket, the vegetables we had at the beginning of the week were perishable. So, necessarily, even if we didn't have the motivation to cook, the vegetables were there, we had to prepare them. There was no alternative. Or I would incur a financial loss. Now, instead of telling myself that I'm going to buy something to start a dish, a big dish that requires cooking time, I'm going to say to myself, "I'm a little tired, we're going to have a pizza or a sandwich.”

According to the participants, this self-discipline had an economic basis (because of an inter-temporal coherence regarding purchasing decisions) but also a temporal basis. As mentioned previously, one of the participants explained that the arrival of the basket encouraged him to plan time to cook its content over the coming days, and this weekly rhythm seems to have played a role 
440 in establishing and maintaining meal preparation routines. When this weekly rhythm was no longer present, many participants said that they needed to really have, as they put it, the "desire” or “energy” to cook.

For one participant this was a matter of having the motivation to cook alone. The change was related not to the way fresh vegetables are purchased but rather to the end of the cooking

445 workshops, which had maintained this motivation. Two other participants also mentioned the loss of psychological and technical support that the workshops provided: one participant stressed the importance of exchanges and conviviality during the workshops, while the other stressed the importance of discovering new recipes in a supportive environment (meaning that mistakes could be corrected and he could have confidence that the dish would ultimately taste good), in

450 maintaining their motivation to cook. Participants expressed that they found it difficult to cook for one person and that the workshops, by offering a time of conviviality and discovery, provided them with an instrumental form of support from this point of view.

The transition back to a conventional food supply system (transition 2a) brought about significant changes. The decrease in the quantity and diversity of fresh vegetables in the

455 participants' diets seems to have resulted from the end of the box scheme. The decline in the proportion of home-cooked meals seems to have been partly attributable to the end of the box scheme as well (since there was no longer any obligation to cook fresh vegetables purchased in advance), and partly attributable to the end of the workshops, because theseworkshops had kept some participants motivated to cook for themselves alone.

460 3. 3. Changes induced by the transition from the experimental box scheme to a classical vegetable box scheme (transition $2 b$ )

This transition involved three participants (one of whom had already had a subscription before the beginning of the study). These participants did not report any significant change, and they reported in particular no change either in the quantity and diversity of fresh vegetables in their 
465 diets, or in the proportion of home-cooked meals they ate. They stated that they continued to receive a vegetable basket and to cook, as they put it, “according to the basket”. They also highlighted the convenience they associated with this mode of supply, as well as the satisfaction they derived from it on a moral level (because of what they viewed as a more ethical food system and because of the well-being they felt when eating quality products and home-cooked meals).

The only changes mentioned by one participant were a slight decrease in the amount of fresh vegetables he ate (this participant had retained a subscription but changed the size of the basket he received) and a loss of creativity by comparison with the period of the experimental box scheme (which this participant attributed to increased professional concerns on his part). On the first point, the size of the basket plays an obvious role. The question of creativity refers to more

475 complex dimensions, which are difficult to disentangle here. The fact that these three participants were all involved in relationships is worth mentioning, as it is possible that this partly explains the maintenance of their ability and willingness to cook regularly.

Two out of these three participants thus profoundly transformed their diet in a relatively lasting way (eight months after the end of the experimental box scheme), thanks to the experimental

480 box scheme itself on the one hand, and the maintenance of a subscription to a conventional vegetable box scheme on the other.

\section{4. Sustainability objectives, long-term change and conceptual framework}

Scholars agree that to reduce the environmental impact of food in high-income countries, food production should involve agroecology and be multifunctional (deliver raw materials but also energy, ecosystem services, and recreation), local, transparent, and coordinated (Rastoin, 2018). They also agree that for the same purpose, food consumption should consist of sufficient but not excessive quantities, be varied and seasonal, and contain fewer energy-dense processed foods, less animal protein, less fat, less sugar, and less salt (Garnett, 2014), be more plant-based (Notarnicola et al., 2017), and more home-cooked (Schmidt Rivera et al., 2014). 

regarding many of the sustainability objectives scholars have highlighted.

Table 2. Sustainability objectives reached after transition 1a

\begin{tabular}{|lll|}
\hline $\begin{array}{l}\text { Changes in the participants' diets after } \\
\text { transition 1a }\end{array}$ & $\begin{array}{l}\text { Number of } \\
\text { participants } \\
\text { who reported } \\
\text { the change }\end{array}$ & Sustainability objectives \\
\hline Increase in vegetable consumption & $9 / 10$ & More plant-based diet \\
\hline Increase in vegetable diversity & $8 / 10$ & Varied and seasonal diet \\
\hline Shopping lists and meal planning & $7 / 10$ & Sufficient, not excessive quantities \\
\hline $\begin{array}{l}\text { Scheduling time for meal preparation } \\
\text { (home-cooking) }\end{array}$ & $4 / 10$ & $\begin{array}{l}\text { Fewer highly processed foods, } \\
\text { less fat, less sugar, }\end{array}$ \\
\hline $\begin{array}{l}\text { Reduction in the cognitive burden related to } \\
\text { buying food (subscription principle) }\end{array}$ & $3 / 10$ & $\begin{array}{l}\text { less salt, } \\
\text { more home-cooking }\end{array}$ \\
\hline $\begin{array}{l}\text { Choice of foods that are: } \\
\text { local, }\end{array}$ \\
\hline $\begin{array}{l}\text { produced according to principles of } \\
\text { agroecology, }\end{array}$ \\
by coordinating producers
\end{tabular}

Regarding the objectives related to sustainable food consumption, the only one that was 495 not addressed by the changes resulting from transition $1 \mathrm{a}$ is a decrease in animal protein consumption. The training aimed to foster such a change, as it is considered an important one, but failed to do so. A first explanation for this failure refers to the targeting of a population of students and young professionals: six out of the 11 participants said they already ate relatively little meat for financial reasons prior to the beginning of the study, which made a reduction in the consumption of 
animal protein difficult to observe during the study. A second explanation refers to the timing of the study. The interviews suggest that such a change may need more time to take place than the 16 months investigated in the study and may also require more training and support if meat is to be replaced by a combination of legumes and cereals. Regarding the objectives related to sustainable food production, two were not addressed: a multifunctional and a transparent supply chain. These 505 objectives were out of the scope of the study from the very beginning, since they would have involved too many changes for the experimental box scheme’s suppliers.

The changes in eating habits observed at the end of transition 1a appear to be reasonably long-lasting, beyond the 3 months duration reported in the previous study by AbuSabha (2016). The interviews conducted while the experimental box scheme was running showed that these changes

510 were present about six months after the start of the scheme, and the interviews conducted eight months after the end of the scheme indicate retrospectively that the changes were maintained until the end of it. The absence of major changes observed in transition $2 \mathrm{~b}$ suggests that the retention of a classical box scheme following the experimental box scheme made it possible to consolidate the initial changes. The addition of food preparation training to a box scheme seems to support the 515 evolution of the subscribers' eating habits as long as the subscription itself lasts.

These changes point to four counter-intuitive value chain-related mechanisms that build a coherent theoretical framework. The box scheme, with its pre-defined perishable content delivered at fixed dates, supported the participants in making more sustainable choices. It allowed for (1) the removal of vegetable price fluctuation, (2) the removal of the cognitive burden of choice, (3) a

520 reduction of the cognitive burden of making shopping lists, and (4) the integration of cooking time in the participants’ weekly schedule. 
Table 3. Value chain-related mechanisms supporting more sustainable consumption

\begin{tabular}{|c|c|c|}
\hline $\begin{array}{l}\text { Changes in } \\
\text { the } \\
\text { participants' } \\
\text { diet }\end{array}$ & Enabling mechanisms & Stylised summary of results \\
\hline $\begin{array}{l}\text { Increase in } \\
\text { vegetable } \\
\text { consumption }\end{array}$ & $\begin{array}{l}\text { Transition 1a evidences that an increase in vegetable } \\
\text { consumption can be supported by the provision of discounted } \\
\text { raw vegetables (and not only free ready-to-eat products, such } \\
\text { as fruit). } \\
\text { Transition 2a points to the crucial role of price fluctuation, } \\
\text { and not of price level only. Vegetable prices tend to fluctuate a } \\
\text { lot more than other prices and this makes the purchasing } \\
\text { decision more difficult than for other products (that are less } \\
\text { perishable or season-dependent and for which habits tend to } \\
\text { override price comparison). }\end{array}$ & $\begin{array}{l}\text { Price fluctuation was a barrie } \\
\text { for sustainable choice, and } \\
\text { the box scheme removed it. }\end{array}$ \\
\hline $\begin{array}{l}\text { Increase in } \\
\text { vegetable } \\
\text { diversity }\end{array}$ & $\begin{array}{l}\text { Transitions 1a, 2a and 2b suggest it is important to } \\
\text { differentiate between choice and diversity. Although choice } \\
\text { was restricted within the box scheme (participants have to put } \\
\text { up with the content of the basket the producers determined } \\
\text { each week), diversity increased. The box scheme supports } \\
\text { diversity by facilitating access to vegetables that are not } \\
\text { usually available in supermarkets (because of their taste, } \\
\text { reputation, preparation techniques...) and that the participants } \\
\text { would not purchase by themselves (for the same reasons). }\end{array}$ & $\begin{array}{l}\text { A restricted choice can } \\
\text { support a more diverse diet. }\end{array}$ \\
\hline $\begin{array}{l}\text { Preparation } \\
\text { of shopping } \\
\text { lists and } \\
\text { planning of } \\
\text { meals }\end{array}$ & $\begin{array}{l}\text { Transitions 1a, 2a and 2b evidence that an effective way to } \\
\text { support meal planning consists of providing an amount of } \\
\text { vegetables that will be the basis for other purchases and meal } \\
\text { design. This approach is less demanding on a cognitive and } \\
\text { material plane than traditional shopping lists and meal } \\
\text { planning based on cooking recipes. }\end{array}$ & $\begin{array}{l}\text { Reducing the cognitive } \\
\text { burden of choice at the } \\
\text { purchasing stage with a } \\
\text { shopping list based on, and } \\
\text { constrained by, fresh goods } \\
\text { already present tends to } \\
\text { reduce the cognitive burden } \\
\text { of meal planning compared to } \\
\text { a situation where this } \\
\text { planning is made each time } \\
\text { from scratch. }\end{array}$ \\
\hline $\begin{array}{l}\text { Time } \\
\text { schedule for } \\
\text { meal }\end{array}$ & $\begin{array}{l}\text { Transitions } 2 \mathrm{a} \text { and } 2 \mathrm{~b} \text { suggest that meal planning is an } \\
\text { implicit component of a vegetable box scheme : the scheduled }\end{array}$ & $\begin{array}{l}\text { Planning enough time for } \\
\text { sustainable choices can be }\end{array}$ \\
\hline
\end{tabular}




\begin{tabular}{|c|c|c|}
\hline preparation & $\begin{array}{l}\text { delivery rhythm pushes the participants to schedule time to } \\
\text { cook the vegetables before decay. A constraint on the } \\
\text { participants' time use results in an improvement in action } \\
\text { planning. }\end{array}$ & $\begin{array}{l}\text { supported by the delivery of } \\
\text { goods at fixed dates. }\end{array}$ \\
\hline
\end{tabular}

At the time of purchase, scholars evidenced that many barriers hinder sustainable choices

525 (Grunert, 2011). In the case of food decisions, price fluctuations, a broad choice, and cognitive burdens regarding meal planning and scheduling appear to be important additional ones. Sustainable products tend to be disadvantaged, typically because seasonal products, organic products and raw products are affected by these barriers. This is reinforced by the frequency of purchasing decisions, that tends to make the barriers more salient. Environmentally more efficient

530 choices are challenged, as illustrated by figure 2 .

Figure 2. Repeated short-term choices towards sustainability are a challenge for consumers

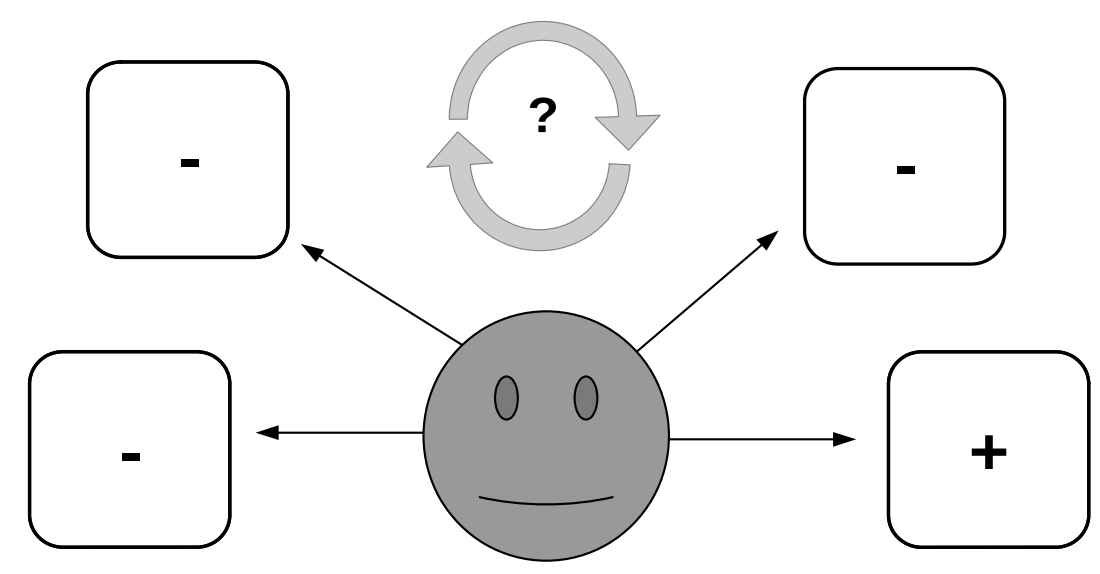


The experimental box scheme of this study provided the participants with means to 540 overcome these barriers by removing price fluctuations, restricting choice but not diversity, and alleviating cognitive burdens related to home-cooking. These changes were performed at two stages, as illustrated by figure 3. First, a single-long term choice removes price fluctuations and ring-fences sustainable options, and second, training supports competence building for handling these sustainable options.

545 Fig 3. Single long-term choice helps consumers choosing more sustainable products while competence building maintains their ability to use and value them.

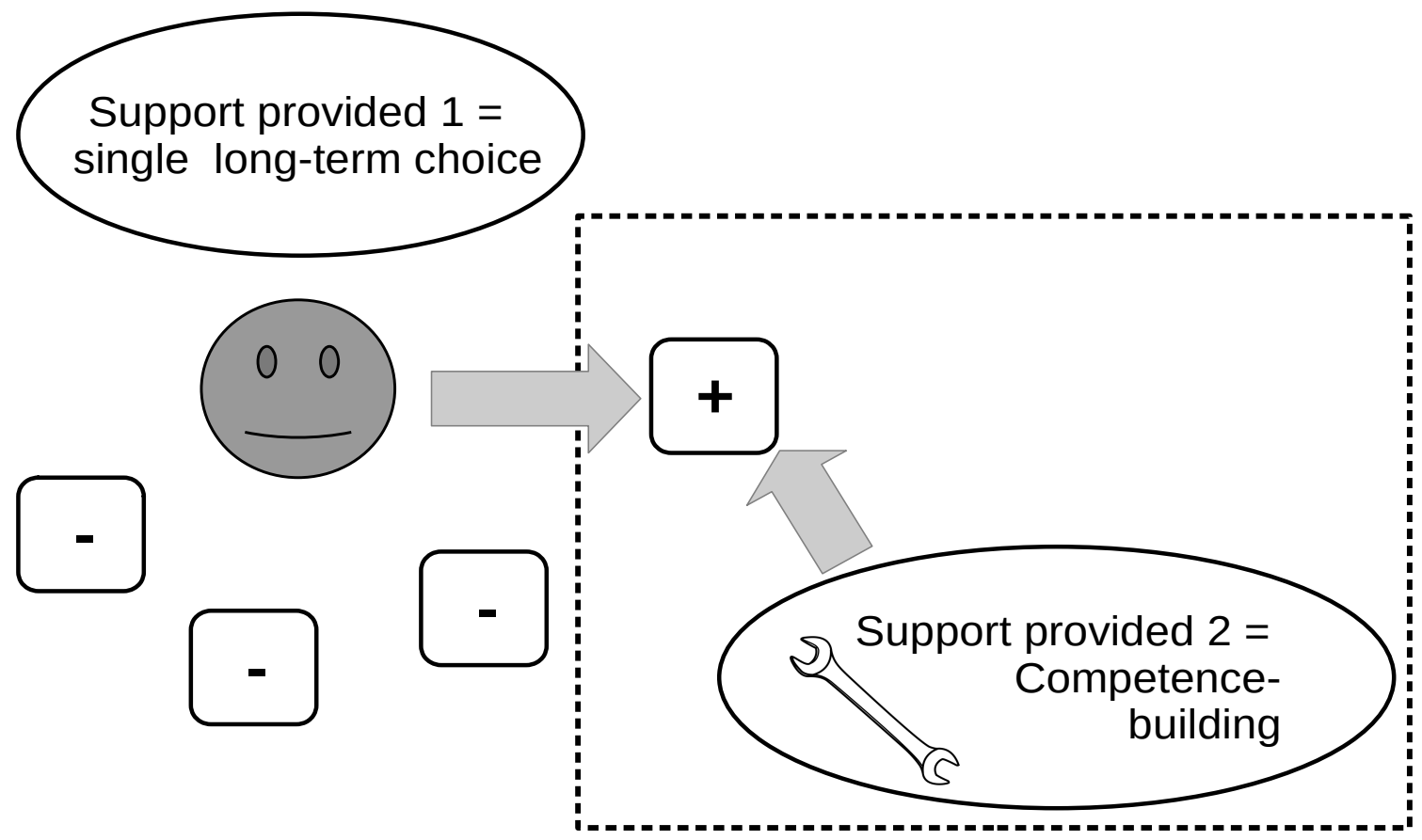

\section{Discussion}


In the case of participants who were initially not particularly willing to engage in more

550 ethical or environmentally sustainable consumption practices, who ate few vegetables, and who had few cooking skills, there were significant changes towards a more sustainable diet when they were supplied with the combination of (1) a weekly basket of local and organic vegetables, and (2) a time-limited, eight-month-long training course providing cooking and organisational skills. These changes persisted for all participants as long as they were using the experimental box scheme, and

555 after the end of this scheme for those who subscribed to a classical vegetable box scheme. These results confirm existing results regarding the potential of box schemes to contribute to eating behaviour change by facilitating vegetable purchase (AbuSabha, 2016) and go further by evidencing that this change can contribute not only to healthier but also to more sustainable diets, and can be maintained in the long run if appropriate food preparation skills are provided.

Although this study is based on a small number of participants in a single region in France, the changes observed among the participants were massive (at the level of each participant and at the level of the group) and consistent with observations made for larger populations elsewhere (327 participants in the United States (AbuSabha, 2016)). The role of food preparation skills in overcoming the organisational challenge of consuming fresh vegetables on a daily basis over a long time evidenced in this study is coherent with the results of other studies that highlighted the preference for simple rules of conduct (Schulte-Mecklenbeck et al., 2013), for pre-commitment (Schwartz et al., 2014), or for a reduction of the cognitive demands of choice (Allan et al., 2015). Further studies would be needed to quantitatively assess the magnitude of the changes in subscribers' diets and their impact on the sustainability of these diets. The qualitative results highlight four counter-intuitive mechanisms that had not been identified previously. First, price fluctuations appeared to play a key role in the participants' decision not to purchase fresh vegetables in transition 2a. This is interesting as previous studies have generally focused on price level, not price stability (Aschemann-Witzel and Zielke, 2017). 
Second, a restricted choice resulted in a more diverse diet. This challenges the commonly admitted

575 view that the broader the choice, the broader the diversity of a diet. This is, however, in line with classical results of psychological research that demonstrated that choice can be a cognitive and emotional burden resulting in negative outcomes (Schwartz, 2004). Third, food experts have long been aware of the cognitive burden of shopping lists and meal planning. They usually tried to address it by improving consumers' skills, often with a focus on technical food preparation skills 580 that are associated with healthier food choices (Hartmann et al., 2013). It seems that providing a basis of seasonal raw foods and adequate food preparation competences could be an alternative way to address this cognitive and organisational burden. Fourth, food experts are aware of the importance of time and time pressure for sustainable diets. The usual answer to this problem has been to look for ways to decrease cooking time by helping consumers planning meals in advance

585 (Lavelle et al., 2016). It seems that food delivery on a fixed-term basis (such a box schemes or traditional street markets) can play an important role in this respect, with the advantage to foster the consumption of fresh local foods. These four findings suggest that a structural transformation of the food value chain can play a key role in supporting more sustainable diets.

The subscription principle may be of broader relevance for other types of purchasing 590 decisions and sustainable consumption. A subscription implies that a decision is taken once for a relatively long period of time. The participants viewed this decision mode as key to increasing and diversifying their vegetable consumption: they had committed themselves at the start of the study with a validity of eight months, and they did not have the opportunity to really question this decision later on. Several participants said that they had made this decision with the explicit aim of

595 increasing and diversifying their consumption of vegetables when they registered for the training and that the subscription system, by construction, had reinforced it each week. On the contrary, when decisions regarding the nature of the food purchases and the fraction of vegetables therein 
must be renewed each week, it is more likely to be challenged, as the participants experienced during transition 2a.

600

Skills provision played a key role in the long-lasting modification of the participants' eating patterns. This point may be of broader conceptual relevance for sustainable production. Most of the participants were at first challenged by the content of the box: they initially believed that they did not like vegetables, many of those they had never eaten, that they were unable to prepare, and they were not used to eating large amounts of them. The training helped them overcome these

605 barriers and went further by enabling them to enjoy as many vegetables as possible and value the freshness and the taste of the vegetables they were provided with, thus realising they could call them “quality products”. Such a learning process may be relevant for other areas of sustainable consumption, where consumers need the skills and support to appreciate a product that is environmentally more efficient but whose use is less straightforward than for its environmentally

610 less efficient counterparts (for instance, regarding mobility). In this context, delivering a product that is sustainable is not enough. The cognitive means and competences needed to use it in a satisfying way in the long run must also be provided.

A last point of broader conceptual relevance has to do with transition 2a: why did the participants choose not to subscribe again and gage up a food supply system that was more

615 sustainable, healthier and for many of them rather satisfying? Beyond practical reasons with limited relevance for other topics (for example, the pick-up point was too far away or a temporary move to another city made a re-subscription pointless), it is worth noting that the participants who decided to carry on explained that they had come to consider the box scheme necessary for their own wellbeing, on a physical as well as on a moral level. They did not wish to give up what they termed as

620 the quality of the products, the convenience of the box scheme, or the removal of the cognitive burden of choice. This match between the box scheme and their own perceived needs, and not only with sustainability objectives or even health objectives, was crucial for their long-term 
consumption. Similarly, it can be hypothesised that a shift towards more sustainable consumption patterns in other fields needs to be perceived as directly physically and morally relevant, necessary

625 and enjoyable for the consumers themselves, and not only for the future of society as a whole.

\section{Conclusion}

These results confirm the need for a comprehensive approach to value chains to make them more sustainable and for experimentation with alternative production systems for fostering behaviour changes in consumers. This approach focuses on ways to generate complete food diets

630 (not individual dishes or meals) that are environmentally sustainable, while satisfying human nutritional needs and that the general public is willing and able to consume, specifically from gustatory and economic perspectives. This implies considering the complete supply chain of valueadding operations from farm to fork, including those operations that can be performed in the nonmonetary part of our economies, such as home cooking. In this respect, the subscription principle is

635 promising. It alleviates the under-estimated cognitive burden of choice at purchasing stage (and consumers' struggle with fluctuating prices, diversity and planning ahead) and helps the consumers stay focused on using their skills to make the most out of the products. The subscription principle and skills-provision services are examples of some components that sustainable alternative production systems may need in the food sector, but they may be of relevance in other contexts,

640 such as mobility or circular economy for example. An adequate design of supply chains seems a promising alternative way to foster more sustainable choices.

\section{Funding sources}

We want to thank the editors and reviewers of the JCP for their constructive comments on 645 an earlier version of this paper. This work was supported by the regional authority Région Hauts de France. 


\section{Declaration of Interests}

None.

650

\section{References}

AbuSabha, R. (2016). The Effects of a Local Produce Subscription Program : Increasing Vegetable Intake and Variety in Working Adults. Journal of the Academy of Nutrition and Dietetics, 116(9), A59. https://doi.org/10.1016/j.jand.2016.06.205

655 Allan, J. L., Johnston, M., \& Campbell, N. (2015). Snack purchasing is healthier when the cognitive demands of choice are reduced: A randomized controlled trial. Health Psychology, 34(7), 750-755. https://doi.org/10.1037/hea0000173

Aschemann-Witzel, J., Zielke, S., 2017. Can’t Buy Me Green? A Review of Consumer Perceptions of and Behavior Toward the Price of Organic Food. J Consum Aff 51, 211-251. https://doi.org/10.1111/joca.12092

Baudry, J., Péneau, S., Allès, B., Touvier, M., Hercberg, S., Galan, P., ... Kesse-Guyot, E. (2017). Food Choice Motives When Purchasing in Organic and Conventional Consumer Clusters : Focus on Sustainable Concerns (The NutriNet-Santé Cohort Study). Nutrients, 9(2), 88. https://doi.org/10.3390/nu9020088

665 Boltanski, L., \& Thévenot, L. (2006). On justification : Economies of worth. Princeton: Princeton University Press.

Brown, E., Dury, S., \& Holdsworth, M. (2009). Motivations of consumers that use local, organic fruit and vegetable box schemes in Central England and Southern France. Appetite, 53(2), 183-188. https://doi.org/10.1016/j.appet.2009.06.006

670 Corbin, J. M., \& Strauss, A. L. (2008). Basics of qualitative research : Techniques and procedures for developing grounded theory (3rd ed). Los Angeles, Calif: Sage Publications, Inc.

Garnett, T. (2013). Food sustainability : Problems, perspectives and solutions. Proceedings of the Nutrition Society, 72(1), 29-39. https://doi.org/10.1017/S0029665112002947

Garnett, T. (2014). Changing what we eat : A call for research \& action on widespread adoption of sustainable healthy eating. Food Climate Research Network, University of Oxford.

Garnett, T., Mathewson, S., Angelides, P., \& Borthwick, F. (2015). Policies and actions to shift eating patterns: What works? A review of the evidence of the effectiveness of interventions aimed at shifting diets in more sustainable and healthy directions. Food Climate Research Network, University of Oxford. 
680 Granvik, M., Joosse, S., Hunt, A., \& Hallberg, I. (2017). Confusion and MisunderstandingInterpretations and Definitions of Local Food. Sustainability, 9(11), 1981. https://doi.org/10.3390/su9111981

Grunert, K. G. (2011). Sustainability in the Food Sector: A Consumer Behaviour Perspective. International Journal on Food System Dynamics, Vol 2, 207-218 Pages. 685 https://doi.org/10.18461/ijfsd.v2i3.232

Hartmann, C., Dohle, S., Siegrist, M., 2013. Importance of cooking skills for balanced food choices. Appetite 65, 125-131. https://doi.org/10.1016/j.appet.2013.01.016

Hoek, A. C., Pearson, D., James, S. W., Lawrence, M. A., \& Friel, S. (2017). Shrinking the foodprint : A qualitative study into consumer perceptions, experiences and attitudes towards healthy and 690 environmentally friendly food behaviours. Appetite, 108, 117-131. https://doi.org/10.1016/j.appet.2016.09.030

Larson, N., Laska, M. N., Story, M., \& Neumark-Sztainer, D. (2012). Predictors of Fruit and Vegetable Intake in Young Adulthood. Journal of the Academy of Nutrition and Dietetics, 112(8), 1216-1222. https://doi.org/10.1016/j.jand.2012.03.035

695 Lavelle, F., McGowan, L., Spence, M., Caraher, M., Raats, M.M., Hollywood, L., McDowell, D., McCloat, A., Mooney, E., Dean, M., 2016. Barriers and facilitators to cooking from 'scratch' using basic or raw ingredients: A qualitative interview study. Appetite 107, 383-391. https://doi.org/10.1016/j.appet.2016.08.115

Markussen, M., Kulak, M., Smith, L., Nemecek, T., \& Østergård, H. (2014). Evaluating the 700 Sustainability of a Small-Scale Low-Input Organic Vegetable Supply System in the United Kingdom. Sustainability, 6(4), 1913-1945. https://doi.org/10.3390/su6041913

Milestad, R., Kummer, S., \& Hirner, P. (2017). Does scale matter? Investigating the growth of a local organic box scheme in Austria. Journal of Rural Studies, 54, 304-313. https://doi.org/10.1016/j.jrurstud.2017.06.013

705 Notarnicola, B., Tassielli, G., Renzulli, P. A., Castellani, V., \& Sala, S. (2017). Environmental impacts of food consumption in Europe. Journal of Cleaner Production, 140, 753-765. https://doi.org/10.1016/j.jclepro.2016.06.080

Poore, J., \& Nemecek, T. (2018). Reducing food's environmental impacts through producers and consumers. Science, 360(6392), 987-992. https://doi.org/10.1126/science.aaq0216

710 Rastoin, J.-L. (2018). Éditorial: Accélérer la transition vers une alimentation durable par un changement de paradigme scientifique et économique et des politiques publiques innovantes. 11 pages, pages 17-27. https://doi.org/10.15122/isbn.978-2-406-08722-9.p.0017

Schanes, K., Giljum, S., \& Hertwich, E. (2016). Low carbon lifestyles : A framework to structure consumption strategies and options to reduce carbon footprints. Journal of Cleaner Production, 139, 1033-1043. https://doi.org/10.1016/j.jclepro.2016.08.154

Schmidt Rivera, X. C., Espinoza Orias, N., \& Azapagic, A. (2014). Life cycle environmental 
impacts of convenience food: Comparison of ready and home-made meals. Journal of Cleaner Production, 73, 294-309. https://doi.org/10.1016/j.jclepro.2014.01.008

Schulte-Mecklenbeck, M., Sohn, M., de Bellis, E., Martin, N., \& Hertwig, R. (2013). A lack of 720 appetite for information and computation. Simple heuristics in food choice. Appetite, 71, 242-251. https://doi.org/10.1016/j.appet.2013.08.008

Schwartz, B., 2004. The paradox of choice: why more is less, 1st ed. ed. Ecco, New York.

Schwartz, J., Mochon, D., Wyper, L., Maroba, J., Patel, D., \& Ariely, D. (2014). Healthier by $\begin{array}{llll}\text { Precommitment. Psychological 538-546. } & \text { Science, }\end{array}$

725 https://doi.org/10.1177/0956797613510950

Shi, J., Visschers, V. H. M., Bumann, N., \& Siegrist, M. (2018). Consumers' climate-impact estimations of different food products. Journal of Cleaner Production, 172, 1646-1653. https://doi.org/10.1016/j.jclepro.2016.11.140

Smith, B. G. (2008). Developing sustainable food supply chains. Philosophical Transactions of the 730 Royal Society B: Biological Sciences, 363(1492), 849-861. https://doi.org/10.1098/rstb.2007.2187

Tait, P., Saunders, C., Guenther, M., \& Rutherford, P. (2016). Emerging versus developed economy consumer willingness to pay for environmentally sustainable food production : A choice experiment approach comparing Indian, Chinese and United Kingdom lamb consumers. Journal of Cleaner Production, 124, 65-72. https://doi.org/10.1016/j.jclepro.2016.02.088

735 Thom, A., \& Conradie, B. (2013). Urban agriculture's enterprise potential : Exploring vegetable box schemes in Cape Town. Agrekon, 52(sup1), 64-86. https://doi.org/10.1080/03031853.2013.770953

Tilman, D., \& Clark, M. (2014). Global diets link environmental sustainability and human health. Nature, 515(7528), 518-522. https://doi.org/10.1038/nature13959

\section{A. Tukker, E. Sto, C. Vezzoli}

"The governance and practice of change of sustainable consumption and production." Introduction to the ideas and recommendations presented in the articles in this special issue of the journal of cleaner production

\section{J. Clean. Prod., 16 (2008), pp. 1143-1145}

745 Unčovská, J., \& Ulčák, Z. (2015). Organic box schemes-Fashion or downshifting? The Journal « Agriculture and Forestry », 61(1). https://doi.org/10.17707/AgricultForest.61.1.07

Wu, P.-J., \& Huang, P.-C. (2018). Business analytics for systematically investigating sustainable food supply chains. Journal of Cleaner Production, 203, 968-976. https://doi.org/10.1016/j.jclepro.2018.08.178 
